\title{
Study on End-Wall Slope Stability of Surface Coal Mine under the Condition of Combined Open-Pit Mining with Underground Mining
}

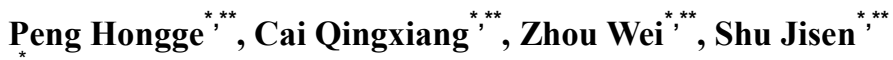 \\ School of Mines, China University of Mining \& Technology, China \\ * State Key laboratory of Coal Resources and Mine Safety, China University of Mining \& Technology, China
}

\begin{tabular}{l}
\hline Article Info \\
\hline Article history: \\
Received Mar 19, 2016 \\
Revised May 4, 2016 \\
Accepted May 20, 2016 \\
\hline Keyword: \\
Combined Mining \\
End-Wall \\
Numerical Simulation \\
Slope Safety \\
Surface Coal Mine
\end{tabular}

Surface Coal Mine

\begin{abstract}
With the deepening of surface coal mine, the application of combined surface mining with underground mining is increased now. According to the influence analysis of underground mining on surface coal mine end-wall slope, the thin plate model of mined slope was proposed with distortion and stress distribution of the girder studied. Considering the practice of combined surface mining with underground mining, the modified method was put forward. Based on the roof breaking law of mined slope, the minimum width of protecting coal pillar was elicited. Subsequently this paper took the combined mining practice of Anjialing surface mine as example to study the subsidence law of roof and the influence of underground mining to surface mine slope. The research conclusion indicates that under the condition of combined mining the deformation and subsidence of overlying strata are obvious with a clear lag time, and the ceiling distortion evokes distortion of mined slope, which can be used as the theory sustainment to stabilization of mined slope under combined surface mining with underground mining.
\end{abstract}

\section{Corresponding Author:}

Peng Hongge,

State Key laboratory of Coal Resources and Mine Safety,

China University of Mining \& Technology,

Xuzhou, Jiangsu 221116, China.

Email: hgpeng@cumt.edu.cn

\section{INTRODUCTION}

China owns rich coal resources, and has a huge annual output. However, the proportion of surface mining production was smaller in the past. Now with the continuing discover of huge coalfields in the central and western China, and the gradual familiarity with the advantages of surface mining, the number of open pit mines grows rapidly and the output is also increasing. Because of security, economy and other factors, surface mining can't be applied to exploit the coal below the end-wall. However, if underground mining method is applied, the end-wall slopes of surface mine will suffer dual disturbances from surface mining and underground mining, which will influence the slope stability greatly. In view of this, end-wall slope stability under the combined mining is a new and challenge research topic. On the basic of theory analysis and field investigation, we attempt to study it preliminarily.

\section{MODELING ANALYSIS OF UNDERGROUND MINING BELOW END-WALL SLOPE ${ }^{[2]}$}

Normally, the dip of strata in surface coal mines is small. To highlight the problem of slope stability, the geological conditions are simplified. It is assumed that the strata are buried horizontally, and then the dip is $0^{\circ}$. The slope angle of surface mine is $\beta$, the thickness of coal seam is $h$, and the height of overburden 
strata is $h_{i}(i=1,2 \ldots n$ from bottom to top). Along with the different layouts of underground mining working face, the models can be established as follows.

\subsection{Establishment of Mining Model}

\subsubsection{Mining Model of Transverse Mining Working Face}

If the underground mining working face lies transversely, which means it goes forward or backward facing the slope and the mining model can be established as Figure 1. In this case, it needs to retain a certain width protective coal pillar between underground mining working face and surface mine slope.

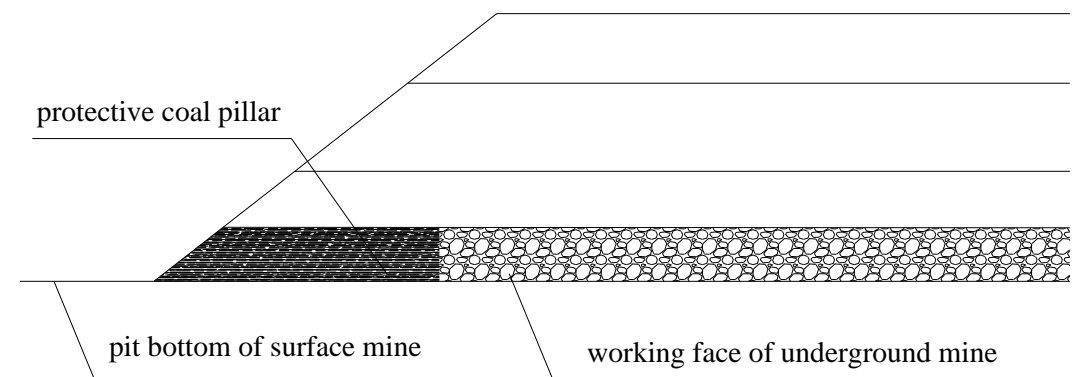

Figure 1. Sketch Of Underground Mining Working Face Lay Transversely Below End-Wall Slope

\subsubsection{Mining Model of Lengthways Mining Working Face}

If the underground mining working face lays lengthways that means it parallels with slope tend towards, the mining model can be established as Figure 2. With this mining mode, it also needs to retain a certain width protective coal pillar near the side of the open pit slope.

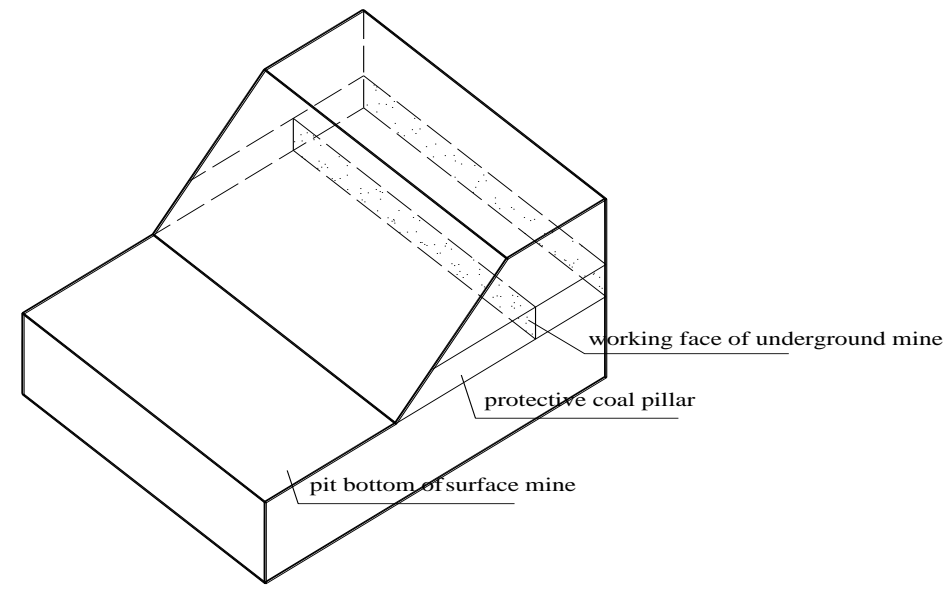

Figure 2. Sketch Of Underground Mining Working Face Parallel To Slope Below End-Wall Slope

\subsection{Mining Model Analysis ${ }^{[3,5]}$}

In surface mines, most of the rock layers are sedimentary rocks, which are with weak physical and mechanical properties. As a result, the thin plate theory can be applied to study instability and collapse mechanism of overburden strata caused by underground mining, and then the mechanical model of roof rock subsidence can be established. With the adjustment according to practice, the subsidence rule of weak sedimentary roof can be drawn after numerical analysis.

In condition of mining single thick coal seam, full collapse mining can be applied to mine the coal below the end-wall slope. Whether the underground mining working face goes towards to or parallels to slope, it is appropriate to take one unit length along the advancing direction. Then the simply supported thin beam model is established as Figure $3^{[1,4]}$. Here the unit length can be considered as the roof caving distance or the advancing length of the coal mining face in periodic weighting. 


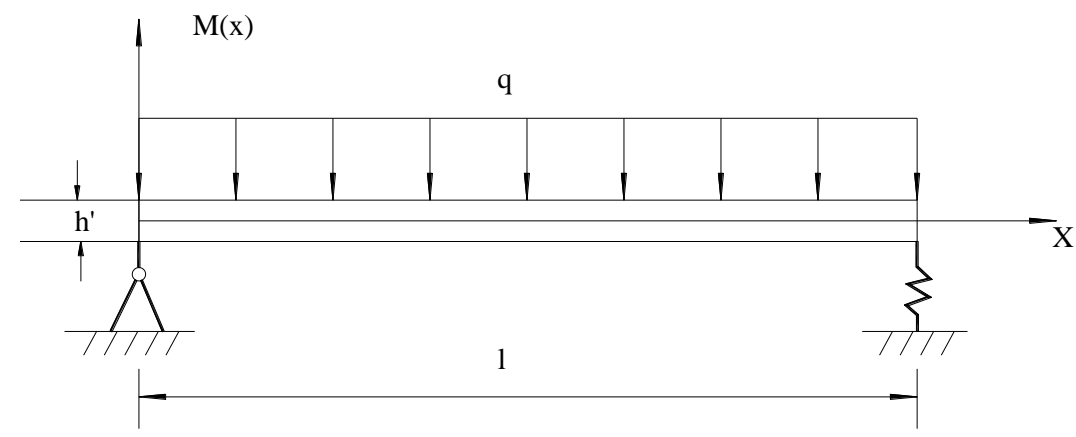

Figure 3. Roof Mechanical Model of Underground Mining Working Face

The cross-section moment is:

$$
M(x)=\frac{q l x}{2}+\frac{q x^{2}}{2}(0<x<1)
$$

where $q$ is unit distributed load, $l$ is plate girder length.

The maximum bending moment presents in the middle section of beam which is also the middle of underground mining working face advancing direction. The maximum bending stress presents in the middle of the upper and lower beam section of the edge, and the value can be expressed as:

$$
\delta_{\max }=\frac{M_{\max }}{b h^{12} / 6}
$$

where $b$ is calculating width, $h^{\prime}$ is roof thickness which can be considered as the thickness of overlying immediate roof.

It can be included from above two formulas as follows:

$$
\delta_{\max }= \pm \frac{3 q l^{2}}{4 b h^{\prime 2}}
$$

The interaction of every stratum should be considered in practice. The rock cohesion between the particles will influence the maximum moment, maximum bending stress and the subsidence. At the same time, the rock cohesion difference of particles between different strata is great which can't be expressed as exact value. So we put forward an amending method by using a coefficient as follows:

$$
M(x)=k_{i}\left(\frac{q l x}{2}+\frac{q x^{2}}{2}\right),(0<x<1), \delta_{\max }= \pm \frac{3 k_{i} q l^{2}}{4 b h^{\prime 2}}
$$

where $k$ is the moment correction coefficient which differs according to different rock properties. For example, $k$ can take a large value if rock cohesion is great such as sandstone; otherwise a small value such as mudstone or limestone. It should be noticed that $k_{1}$ is applied to the moment and stress distribution of the first stratum, and $k_{2}$ to the second stratum, and so on. According to the coefficient correction, the gap between theoretical analysis and practice will be smaller than ever.

It is set five paces along advancing direction of underground mining working face to represent the regular intervals of roof collapse. The stress distribution contours of overlying strata can be educed which is caused by underground mining below end-wall slope ${ }^{[2]}$. 


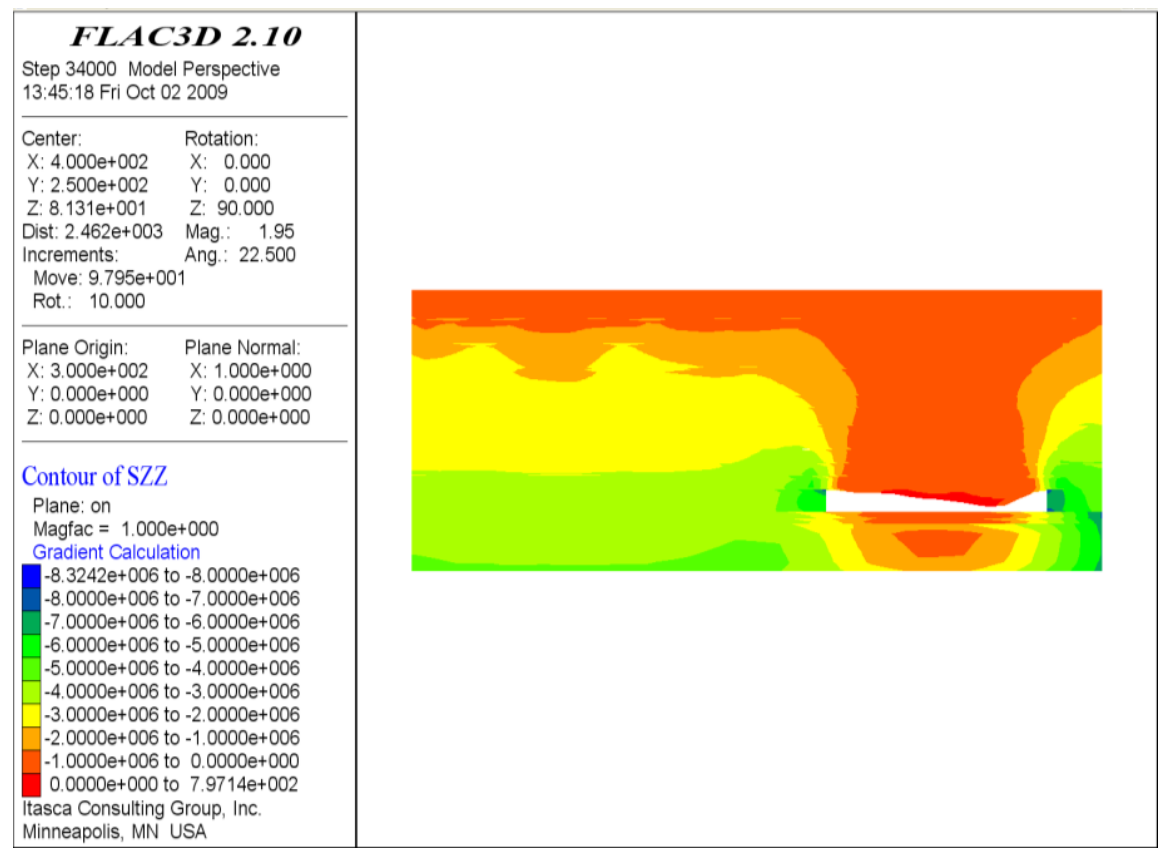

Figure 4. Vertical Stress Distribution of Section Plane of the Underground Working Face Perpendicular to Advancing Direction

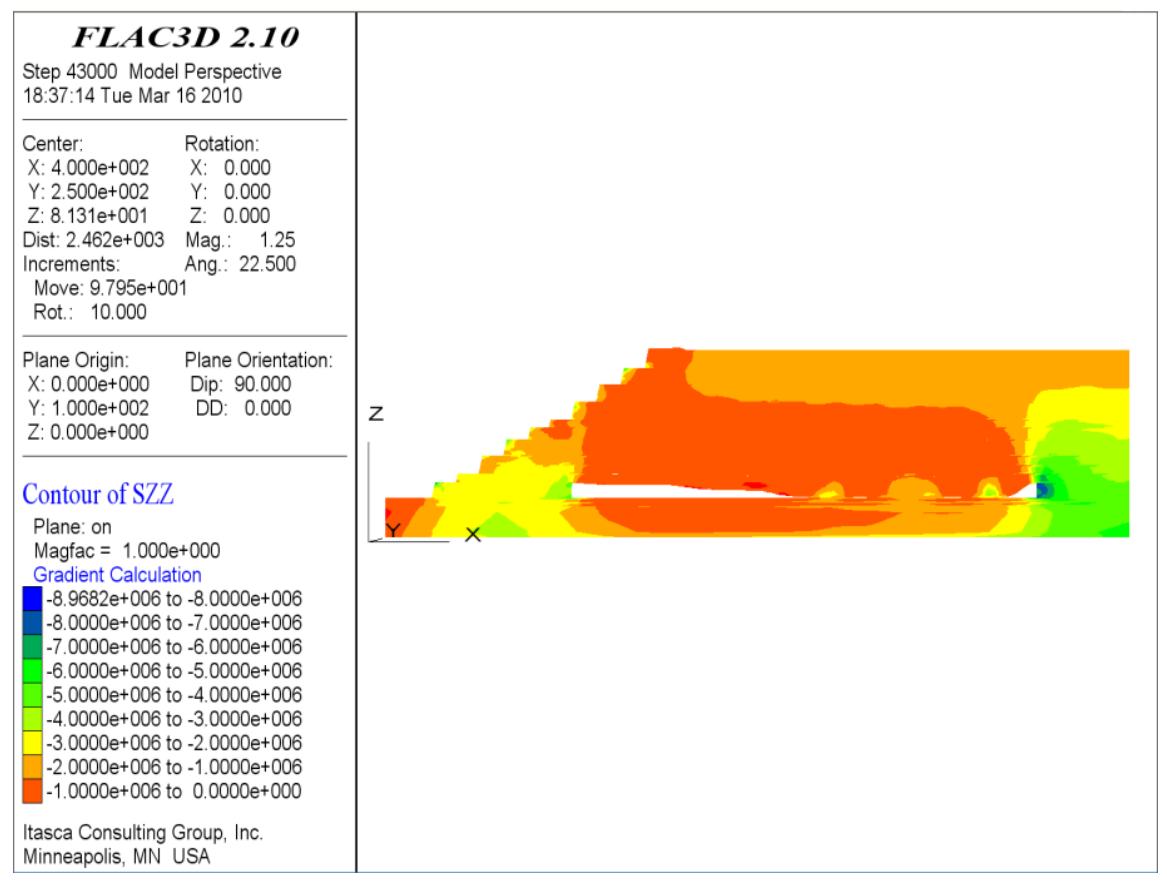

Figure 5. Vertical Stress Distribution of Section Plane in Working Face with 150m Protecting Coal Pillar 


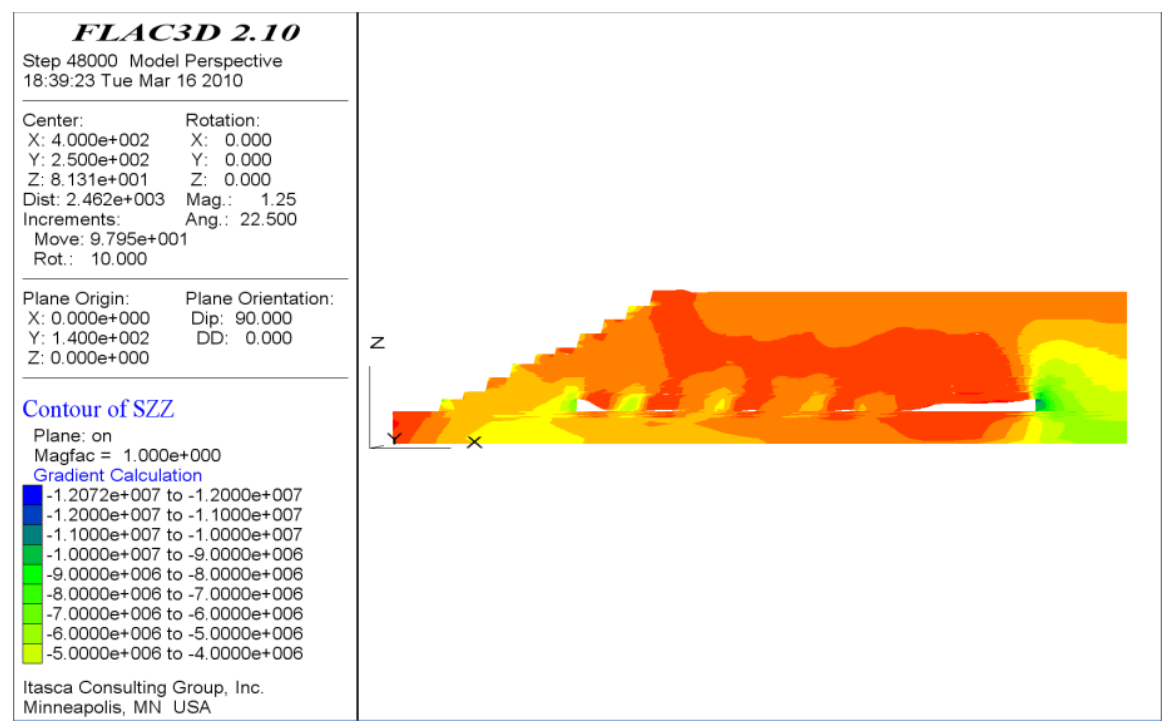

Figure 6. Vertical Stress Distribution of Section Plane in Working Face with 150m Protecting Coal Pillar.

From the stress distribution contours above it can be known that whether in forward direction or in reverse direction, underground mining will cause subsidence of overlying strata. Because of the cohesion force of rock and the particles, there is a clear lag time of the stress diversification and subsidence of overlying strata, which inosculates to the field observations. And the modified theory is also validated.

\section{STOPPING MINING LINE}

It is called stopping mining line that the position where mining working face starts when it goes in reverse direction to the slope or ends when it goes in forward direction to the slop. The distance between the position and the slope is also called width of protecting coal pillar. From above analysis results, we also know that the collapse or subsidence of overlying strata will impact the safety of slope, buildings, transportation roads and equipment seriously. Consequently, it is necessary to determine the stopping mining line to surface mine or underground mine.

The determination principle of stopping mining line is the subsidence or collapse area will not harm to the safety of surface mine slope or transportation roads. Large subsidence area shapes behind the slope after the underground mining. So the subsidence rock will bring positive pressure to slope, as shown in Figure 7.

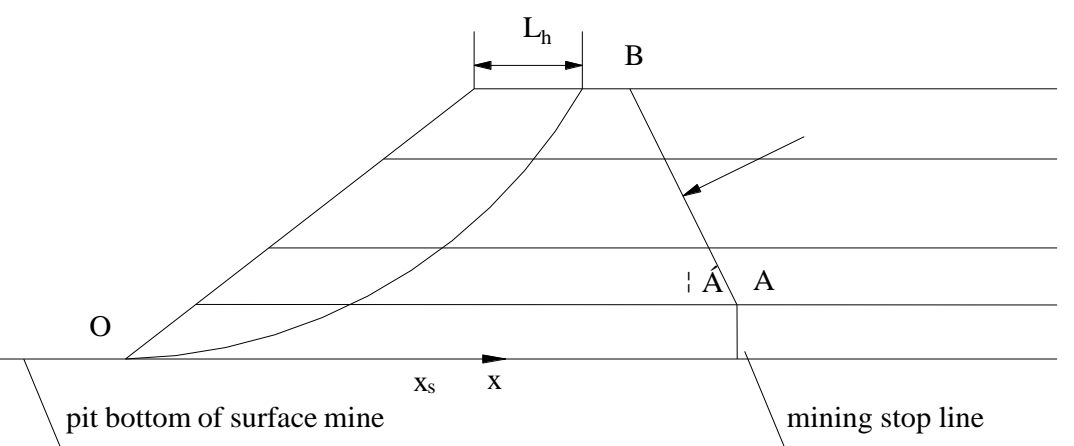

Figure 7. Sketch Map of Subsidence Area Influencing Surface Mine Slope.

In the slope stability analysis there is a circular surface most likely to slip which extends to top slope. The distance between the exposing point and the top line of slope is $L_{\mathrm{h}}$. Then the coordinate system can be 
established. Slope toe is the coordinate origin, $X$ axis is the right extension direction. Assuming the mining stop line $X_{\mathrm{s}}$ is $A$, subsidence angle is $\alpha$, the conclusion is followed as :

1) When $\alpha$ is bigger than $L_{\mathrm{h}}+H \cot \alpha$, subsidence area keeps away from the face that is most likely to slip, which has no influence on slope stability.

2) When $\alpha$ is equal to $L_{\mathrm{h}}+H \cot \alpha$, subsidence area just begins to enter the face, which has little influence on slope stability.

3) When $\alpha$ is smaller than $L_{\mathrm{h}}+H \cot \alpha$, subsidence area is in the face, which has great influence on slope stability. In this case the coefficient of slope stability is:

$$
F_{\mathrm{s}}=\frac{\sum\left(C l_{i}+\tan \varphi W_{i} \cos \beta_{i}\right)}{F_{\mathrm{r}}+\sum W_{i} \sin \beta_{i}}
$$

where $F_{r}$ is partial strength of $N$ entering the sliding area, $C$ is the rock cohesion, $W_{i}$ is the gravitation of no. $\mathrm{i}$ strip, $\varphi$ is the internal friction angle of rock, $\beta_{i}$ is the sliding face angle of no. $\mathrm{i}$ strip.

\section{CASE STUDY}

The paper takes Anjialing surface mine as the example. Anjialing surface mine and underground mine locate in the south-central Pingshuo mine area. There are three coal seams: $4^{\#}, 9^{\#}$ and $11^{\#}$. Actual production capacity of surface mine has reached $15 \mathrm{Mt} / \mathrm{a}$. Underground mine exploits $4^{\#}$ coal seam mainly, and the raw coal output reaches $8 \mathrm{Mt} / \mathrm{a}$. The relation between 902 working face and the slope is shown as Figure 8.

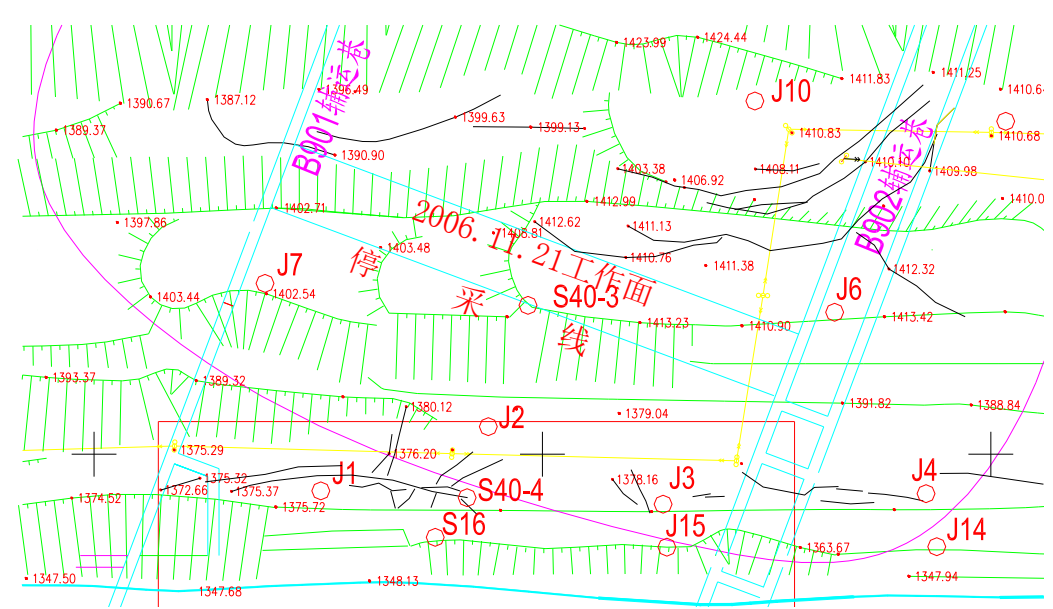

Figure 8. Relation between the 902 working face and the slope location.

Based on the engineering geological dada that have already been collected, calculation parameters are selected as shown in Table 1.

Table 1. The Main Mechanical Properties of Rock.

\begin{tabular}{lllll}
\cline { 1 - 1 } sandstone & \multicolumn{2}{c}{ Bulk density $\left(\mathrm{kN} / \mathrm{m}^{3}\right)$} & Cohesion $(\mathrm{kPa})$ & Internal friction angle $\left(^{\circ}\right)$ \\
coal seam & 24.8 & 350 & 149 & 31 \\
mudstone & 14.9 & 318 & 26.5 \\
loess & 23.7 & 23 & 27 \\
spoil & 19.0 & 19 & 25 \\
sandstone in cross fall area & 18.7 & 23 & 25 \\
\hline
\end{tabular}


According to field monitor dada, the subsidence angle is about $55^{\circ}$. After the B902 working face is finished, the subsidence area has extended to monitor point S40-4, while the influence of horizontal displacement velocity caused by later mining will decrease. The accumulative total displacement of S40-4 is $448 \mathrm{~mm}$ and displacement velocity is $73 \mathrm{~mm} / \mathrm{d}$. The displacement and velocity toward south increase because the elastic area has entered slope area. As a result, the strata angle increased, the down force increased, displacement increased, and so did the velocity.

According to analyzing Anialing surface mine practice with Figure 8, the conclusion can be drawn as follows: when the slope angle is $42^{\circ}$ and the height of slope is $180 \mathrm{~m}$, the stability coefficient is 1.38 , the length of $L_{h}$ is $47 \mathrm{~m}$, the protecting coal pillar is no less than $308 \mathrm{~m}$.

\section{CONCLUSIONS}

Relationship between exposing length and stability coefficient under different slope angle was obtained. Decrease proportion of exposure area under slope angle variations was also analyzed in the paper, and some conclusions are drawn as follows:

(1) Underground mining below surface mine slope will cause subsidence and collapse of overlying strata and influence the surface slope safety. According to the analysis of related mechanical model, the stress distribution mechanism of overburden layers is elicited. The outcome of numerical simulation verifies the correctness of the modified theory.

(2) By the establishment of mined slope calculation model, the stability calculating method is analyzed, the judgment formulae is elicited, with the determination principle and judgment of minimum protecting coal pillar width of slope drawn.

(3) Aiming at reducing mining cost and reclaiming more resources, surface mining and underground mining combine together. In order to reduce the impact on surface mine slope caused by underground mining, various measures should be taken and the following principles should be obeyed. The subsidence area caused by underground mining should not enter the slope area. Periodic weighting length can be shortened according to active releasing roof strata. The mined-out area should be backfilled properly with waste material to reduce the influence of underground mining on surface mine slope.

\section{ACKNOWLEDGEMENTS}

This work was financially supported by the the National 863 Program of China (2012AA062004), China Doctoral Science Foundation (20100095110019), the Independent Research Fund of The State Key Laboratory of Coal Resources and Mine safety(SKLCRSM10X01), the Special Fund for Basic Scientific Research of Central Colleges (2010QNA33, 2010ZDP01A02).

\section{REFERENCES}

[1] Tang X L, Ye M L. The thin plate theory analysis of hard roof and pressure forecast [J]. Ground Pressure and Strata Control. 2003: 2: 89-92. (In Chinese)

[2] Peng H G. Influence Mechanism of mining disturbance on slope stability in surface coal mine [D]. Xuzhou: China University Of Mining And Technology library. 2010. (In Chinese)

[3] Peng H G, Cai Q X, Zhou W, Shu J S, Chen Y L. Study on distortion mechanism of mined slope affected by openpit and underground mining[J]. Metal Mine. 2009: 11: 129-131. (In Chinese)

[4] Peng H G, Cai Q X, Zhou W, Shu J S. Research on key influence factors of end-slope stability for steep end-slope mining in surface coal mine [J]. China Mining Magazine. 2008: 17(5): 71-74. (In Chinese)

[5] Wang Z W, Wang L G, Wang J G. Study on Failure Rule of Rock Slope Affected by Underground Mining[J]. Mining Research and Development. 2009: 29(2): 13-15. (In Chinese)

[6] Peng H G, Cai Q X, Shu J S, Zhang L. Application research of numerical simulation in the slope stability of buzhao-ba open pit [J]. China Mining Magazine, 2007, 16 (6):60-62. (In Chinese) 